\title{
Epidural administration of ketamine or fentanyl with bupivacaine for postoperative analgesia - A comparative study
}

\author{
Abdullah Al Maruf ${ }^{*}$, Iqbal Hosain Chowdhury ${ }^{2}$, Kazi Ashkar Lateef ${ }^{1}$, \\ Manzoorul Haq Laskar ${ }^{3}$, Md. Mustafa Kamal ${ }^{4}$
}

${ }^{1}$ Graded Specialist in Anaesthesiology, Department of Anaesthesia \& Intensive Care, CMH, Dhaka, ${ }^{2}$ Associate Professor
(Intensive Care Unit), Anaesthesia, Analgesia, \& Intensive Care Medicine Dept. BSMMU, Dhaka, ${ }^{3}$ Consultant, Anaesthesia,
Analgesia, \& Intensive Care Medicine Dept. BSMMU, Dhaka, ${ }^{4}$ Assistant Professor, BSMMU, Dhaka
${ }^{*}$ Corresponding auther: Graded Specialist in Anaesthesiology, Department of Anaesthesia \& Intensive Care, CMH, Dhaka,

\begin{abstract}
The purpose of the study was to compare the analgesic effectiveness of epidural administration of ketamine mixed bupivacaine with fentanyl mixed bupivacaine in the management of postoperative pain. This prospective study was carried out in CMH, Bogra in one calendar year from July 2004 to June 2005. For postoperative pain management 100 patients of both sex, age ranging between 20 to 50 years, ASA physical status I and II scheduled for lower abdominal, pelvic and inguinal surgery were included in the study. All patients were divided into two groups. Epidural catheter was inserted in each patient through space between $L_{3}$ to $L_{2}$. Surgery was done under epidural anaesthesia in both groups. In group A ( $\left.n=50\right)$ surgery was done with $0.5 \%$ bupivacaine and fentanyl (bupivacaine $1.5 \mathrm{ml} / \mathrm{segment}+$ fentanyl $2 \mu \mathrm{g} / \mathrm{ml}$ ). In group $B(n=50)$ surgery was done with $0.5 \%$ bupivacaine and ketamine (bupivacaine $1.5 \mathrm{ml} /$ segment + ketamine $0.3 \mathrm{mg} / \mathrm{kg}$ body weight). Epidural analgesia was continued in postoperative ward with $6 \mathrm{ml}$ $0.25 \%$ bupivacaine + fentanyl $2 \mu \mathrm{g} / \mathrm{ml}$ in group A and with $6 \mathrm{ml} 0.25 \%$ bupivacaine + ketamine $0.3 \mathrm{mg} / \mathrm{kg}$ bodyweight in group B, 4 hourly for 24 hours. The efficacy of analgesia was assessed by using Visual Analogue Scale (VAS) and Verbal Rating Scale (VRS). Mean VAS and mean VRS were less than 3 in both groups, which proved adequate postoperative analgesia. Differences of mean VAS and mean VRS between two groups were statistically not significant. Haemodynamic parameters, respiration and oxygenation were within normal range in both groups. Postoperative complications, like inadequate analgesia, post operative nausea and vomiting (PONV), headache and vertigo were less in both groups. It was observed that epidural administration of both bupivacaine mixed with ketamine and bupivacaine mixed with fentanyl found safe, effective and tolerable for postoperative pain management.
\end{abstract}

Key Words: Post operative analgesia, bupivacaine, ketamine, fentanyl, epidural.

(Journal of BSA, 2009; 22(1): 21-25)

\section{Introduction}

Postoperative pain management is an essential part of modern anaesthesia and surgery. Anaesthesiologists generally best manage it, because they offer regional anaesthetic techniques as well as pharmacologic expertise in analgesics. Usually postoperative pain has been treated with intramuscular pethidine as and when basis or 8 hours interval. But study showed that traditional postoperative pain management does not provide adequate postoperative analgesia ${ }^{1}$. Recently there is an increased interest in regional techniques, studies suggest that regional anaesthesia and analgesia especially epidural block can provide better postoperative analgesia and block neuroendocrine response to surgery; the sensory level of block should be above $\mathrm{L}_{1}$ to have a significant effect on cortisol response $^{2}$. Epidural anaesthesia and analgesia can be achieved through any intravertebral space from $\mathrm{C}_{3-4}$ to sacral hiatus ${ }^{3}$. An epidural catheter is used for top ups or continuous infusion of local anaesthetics during postoperative period. Local anaesthetics, short or long acting, remain the foundation of regional anaesthesia. However, local anaesthetics have central nervous and cardiac toxicity in overdose and have other disadvantages 
such as motor blockade, tachyphylaxis or hypotension when used in clinical concentrations. The strategy was to add other substances to local anaesthetics. Apart from epinephrine, opioids were the first drugs to be associated with the local anaesthetics. The efficacy of this mixture has been extensively demonstrated and animal studies showed synergism between these two classes of analgesics ${ }^{4}$. Opioid may be mixed with the local anaesthetic solution to intensify the block or to manage postoperative pain. Opioid receptors are present in level I and II of substantia gelatinosa of the dorsal horn. The clinical behavior of the opioid can be predicted by its lipid solubility. Highly lipid soluble opioids like fentanyl, passes through membranes and binds quickly to the receptors. Fentanyl has a rapid onset, short duration and unlimited spread. However, risk of opioid-induced respiratory depression, so the search for alternative analgesic drugs continues.

Ketamine has been used as an anesthetic analgesic agent for more than 30 years $^{5}$. Ketamine has been reported to produce not only general but also local anesthesia ${ }^{6}$. It also interacts with N-methyl-Daspartate (NMDA) receptors ${ }^{7}$, opioid receptors ${ }^{8}$, monoaminergic receptors ${ }^{9}$, muscarinic receptors ${ }^{10}$, and voltage gated calcium channels ${ }^{11}$. Ketamine has been studied in the epidural route alone or combination with local anaesthetics alternative to local anaesthetic mixed with opioid. The combination of epidural ketamine and bupivacaine increased the level of sensory block, improved analgesia and reduced analgesic consumption compared with bupivacaine alone ${ }^{12}$. This prospective study was designed to compare the analgesic effectiveness of epidural administration of fentanyl mixed bupivacine to ketamine mixed bupivacaine in the management of postoperative pain after lower abdominal, pelvic and inguinal operations.

\section{Materials and Methods}

We performed a prospective study on one hundred patients of both sex, age ranging between 20-50 years, ASA physical status I and II scheduled for routine lower abdominal, pelvic and inguinal operations, who gave written informed consent to the protocol. The study was performed at Combined Military Hospital, Bogra in one calendar year from July 2004 to June 2005 and BSMMU. Patients with known bleeding disorders, sepsis near injection site, previous extensive back surgery were excluded from the study. During preanaesthetic assessment, total procedure was explained to each patient and every patient was familiarized with Visual Analogue Scale (VAS). Each patient was preloaded with $500 \mathrm{ml}$ Hatmann's solution before performing block. Taking all aseptic precautious an $18(\mathrm{G})$ catheter was introduced through $18(\mathrm{G})$ epidural needle between $\mathrm{L}_{2}, \mathrm{~L}_{3}$ space.

Patients were divided into two groups. Group A contained 50 patients received a bolus dose of $0.5 \%$ bupivacaine $1.5 \mathrm{ml} /$ segment with fentanyl $2 \mu \mathrm{g} / \mathrm{ml}$ through epidural catheter. Group B contained 50 patients received a bolus dose of $0.5 \%$ bupivacaine $1.5 \mathrm{ml} /$ segment with ketamine $0.3 \mathrm{mg} / \mathrm{kg}$ body weight through epidural catheter. Level of sensory block was tested by pinprick. Surgery was allowed after 20 minutes of initial dose. Heart rate, blood pressure, ECG and $\mathrm{SpO}_{2}$ were monitored continuously. After completion of operation, all patients were taken to postoperative ward and nursed for 24 hours. In group A, postoperative analgesia was maintained with $6 \mathrm{ml}$ of $0.25 \%$ bupivacaine with fentanyl $2 \mu \mathrm{g} / \mathrm{ml}$, injected through epidural catheter 4 hourly for 24 hours. In group B, postoperative analgesia was maintained with $6 \mathrm{ml}$ of $0.25 \%$ bupivacaine with ketamine $0.3 \mathrm{mg} / \mathrm{kg}$ body weight injected through epidural catheter 4 hourly for 24 hours. Postoperative analgesia was assessed in both groups subjectively by VAS and postoperative nurses assessed pain by mean of Verbal Rating Scale(VRS). Observations were made at 4 hours interval for 24 hours. A rescue dose of intramuscular injection of pethidine $1 \mathrm{mg} /$ $\mathrm{kg}$ bodyweight was given if any patient complained inadequate analgesia. Patient's heart rate, blood pressure, respiratory rate and $\mathrm{SpO}_{2}$ were observed accordingly. Postoperative complications, like inadequate analgesia, post operative nausea and vomiting (PONV), headache and vertigo were also recorded. All results were expressed in percentage or mean+SEM as applicable. Statistical analysis were carried out using Statistical Package for Social Science (SPSS) for Windows version 10.0. Results were considered statistically significant if $\mathrm{P}$ value less than 0.05 .

\section{Results}

Patient's demographics were similar and comparable in both groups and differences were statistically not significant (Table-I). Duration of 
Table-I

Characteristics of patients

\begin{tabular}{lccc}
\hline Parameters & $\begin{array}{c}\text { Group A } \\
(\mathrm{n}=50)\end{array}$ & $\begin{array}{c}\text { Group B } \\
(\mathrm{n}=50)\end{array}$ & $\begin{array}{c}\text { Result Student's } \\
\text { 't' test (unpaired) }\end{array}$ \\
\hline Age (years) & $43.98 \pm 3.11$ & $40.78 \pm 2.87$ & $\mathrm{NS}$ \\
Sex (M/F) & $22 / 28$ & $24 / 26$ & \\
Body Weight (kg) & $52.17 \pm 1.68$ & $53.25 \pm 1.76$ & $\mathrm{NS}$ \\
Height (cm) & $157.48 \pm 1.32$ & $156.36 \pm 1.26$ & $\mathrm{NS}$ \\
Duration of Surgery (min) & $72.34 \pm 4.37$ & $74.85 \pm 5.25$ & $\mathrm{NS}$ \\
\hline
\end{tabular}

Values are Mean \pm SEM

NS - No significant differences between two groups.

Table - II

Types of operation performed

\begin{tabular}{lccc}
\hline Name of operations & Group A (n=50) & Group B (n=50) & Total (n=100) \\
\hline Abdominal hysterectomy & $23(46 \%)$ & $20(40 \%)$ & $43(43 \%)$ \\
Inguinal herniorraphy & $18(36 \%)$ & $22(44 \%)$ & $40(40 \%)$ \\
Uterine myomectomy & $3(6 \%)$ & $4(8 \%)$ & $7(7 \%)$ \\
Sulpingo - oophorectory & $4(8 \%)$ & $2(4 \%)$ & $6(6 \%)$ \\
Appendicectomy & $2(4 \%)$ & $2(4 \%)$ & $4(4 \%)$ \\
\hline
\end{tabular}

surgical procedure was similar in both groups and differences were statistically not significant (TableI). No patient was withdrawn from the study. The types of operation performed were shown in TableII. Operating conditions were pronounced satisfactory by the surgeon concerned in all the cases. In the postoperative period, mean VAS was $2.21 \pm 0.13$ minutes in group A and $2.31 \pm 0.15$ minutes in group B. Mean VAS was more in group $B$ than in group A but difference between two group was statistically not significant.(Table-III). Mean VRS was $2.68 \pm 0.11$ minutes in group $\mathrm{A}$ and $2.87 \pm 0.16$ minutes in group B. Mean VRS was more in group B than in group $\mathrm{A}$, but difference between two group was statistically not significant (TableIII). There were no instances of hypotension, bradycardia, and respiratory depression to both groups during and after administration of epidural drugs during surgery and in postoperative period. Two patients in group $\mathrm{A}$ and four patients in group B complained about inadequate analgesia in first 6 hours after operation and managed with single rescue dose of intramuscular pethidine $1 \mathrm{mg} / \mathrm{kg}$ bodyweight. However, the difference of inadequate analgesia between two groups was statistically not significant. Incidence of postoperative complications like PONV, headache, vertigo were recorded and shown in (Table-IV). Incidence of PONV is more in group $B$ than group $A$ and difference was statistically significant $(p<0.01)$. Incidence of headache and vertigo were similar and less in both groups and differences were statistically not significant. Two patients in group B complained mild transient burning sensation in back during epidural injection of ketamine mixed bupivacaine.

Table-III

Comparison of mean VAS and mean VRS between two groups

\begin{tabular}{lcc}
\hline Groups & VAS & VRS \\
\hline Group A (n=50) & $2.21 \pm 0.13$ & $2.68 \pm 0.11$ \\
Group B (n=50) & $2.31 \pm 0.15$ & $2.87 \pm 0.16$ \\
Result Student's & NS & NS \\
't' test (unpaired) & & \\
\hline
\end{tabular}

Values are Mean \pm SEM

NS - No significant differences between two groups 
Table - IV

Complications during postoperative period

\begin{tabular}{lccccc}
\hline Group & Number & Inadequate analgesia & PONV & Headache & Vertigo \\
\hline Group A & 50 & $2(4 \%)$ & $2(4 \%)$ & $2(4 \%)$ & $2(4 \%)$ \\
Group B & 50 & $4(8 \%)$ & $8(16 \%)$ & $2(4 \%)$ & $4(8 \%)$ \\
Result Chi-square test & - & $\mathrm{NS}$ & $\mathrm{P}<0.01$ & $\mathrm{NS}$ & $\mathrm{NS}$ \\
\hline
\end{tabular}

NS - No significant differences between groups.

$\mathrm{P}<0.01$ - Statistically significant.

\section{Discussion}

Surgery represents a form of legally allowable premeditated injury inflicted on the body of the patient, hence it is reasonable to expect and experience pain after surgery. In spite of recent advances in medical science, in surveys, nearly one third of patients unfortunately still complained inadequate relief of postoperative pain ${ }^{13}$. Postoperative analgesia is usually achieved by timehonoured method of intramuscular injection of pethidine, which is inadequate. In the last few years regional analgesia especially epidural block with catheter technique provide an excellent means of postoperative analgesia. To avoid the complications, risk of local anesthetics, anaesthesiologists seek to reduce the dose of local anesthetics, while maintaining the analgesic efficacy, and different adjuvents were tried. The efficacy of mixture of local anesthetics and opioid has been extensively demonstrated. Animal studies showed synergism between these two classes of analgesics ${ }^{4}$ and opioids act mainly on presynaptic receptors and reduce neurotransmitter release ${ }^{14}$. Since the first publication on the epidural administration of ketamine in human in 1982, various studies on pharmacology, toxicology and clinical use of ketamine by the epidural and intrathecal routes have been published. Ketamine is a phencyclidine derivative, has a chemical structure similar to that of lignocaine and procaine ${ }^{6}$. Ketamine antagonizes NMDA receptors and prevents wind up and long term potentiation ${ }^{14}$. There is considerable evidence that ketamine inhibits spinal transmission of nociceptive stimuli ${ }^{15,16}$.

In this present study, we confirm the previous reports that ketamine exerts significant effects on postoperative pain mechanism. In this study, we tried to compare the analgesic effectiveness of epidural administration of ketamine mixed bupivacaine with fentanyl mixed bupivacaine for postoperative analgesia. We used $0.25 \%$ bupivacine $6 \mathrm{ml}$ with fentanyl $2 \mu \mathrm{g} / \mathrm{ml}$ in group A and $0.25 \%$ bupivacaine $6 \mathrm{ml}$ with ketamine $0.3 \mathrm{mg} / \mathrm{kg}$ bodyweight in group B, 4 hourly through epidural catheter for 24 hours in the postoperative period. The pain intensity was assessed accordingly by using VAS and VRS. The mean VAS and mean VRS was less than 3 in both groups which indicate adequate postoperative analgesia was maintained in both group. However, mean VAS and mean VRS were less in group A than group B, but the differences were statistically not significant.

This analgesic effectiveness of ketamine mixed bupivacaine may correlate the study undergone for postoperative pain management for upper abdominal surgery with epidural ketamine combined with bupivacaine $^{12}$. Ketamine antagonizes NMDA receptors in substantia gelatinosa in the spinal $\operatorname{cord}^{17,18}$. It also interacts with spinal opioid receptors but seems to play a minor role. The affinity of ketamine for opioid receptors may be 10,000 fold weaker than morphine ${ }^{19}$. In vitro and animal studies also suggested ketamine involve the descending inhibitory monoaminergic pain pathways, through inhibition of reuptake of neurotransmitter ${ }^{9}$. With epidural block postoperative analgesia is confined to area of operation, thus minimizing the vasomotor paralysis and haemodynamic stability of postoperative patients are well maintained ${ }^{20}$. In this study patient's haemodynamic parameters were within normal range. There were no reports of hypotension and bradycardia in both groups. Respiratory rate and $\mathrm{SpO}_{2}$ were also acceptable in both groups.

Incidence of postoperative complications like PONV, headache and vertigo were observed in both groups. 
Incidences were less and almost similar in both groups, though PONV was more in group B than group A and difference was statistically significant. Two patients complained mild transient burning sensation in back during epidural administration of ketamine added bupivacaine in group B. This may correlate with study undergone epidural ketamine for postoperative analgesia for gallbladder operation ${ }^{21}$. This mild burning sensation was may be due to ketamine itself and well tolerated by the patients.

\section{Conclusion}

Epidural administration of bupivacaine mixed with ketamine produced satisfactory level of postoperative analgesia. The quality of analgesia did not significantly differ from that of fentanyl added bupivacaine. Both the techniques were found safe, effective and acceptable.

\section{References:}

1. Wilson-Barnett J. Anxiety in hospitalized patients R. Soc Health J.1981; 101:11822.

2. Desborough JP. The stress response to trauma and surgery. Br. J Anaesth 2000; 85: 109.

3. Philip R. Bromage - Epidural Analgesia, WB. Saunders 1978; 6: 176.

4. Vercauterel M. Meert TF: Isobolographic analysis of the interaction between epidural sufentanil and bupivacaine in rats. Pharomacol Biochem Behav.1997; 58: 237-42.

5. Kohrs R, Durieux M. Ketamine; teaching an old drug for new tricks. Anesth Analg 1998-87: 1186-93.

6. Dowdy EG, Kaya K, Gocho Y. Some pharmacological similarities of ketamine, lidocaine, and procaine. Anaesth and Anal 1973; 92: 839-842.

7. Hall R, Murdoch J. Brain protection. Canadian Journal of Anaesthesia 1990; 37: 762 - 777.

8. Hurstveit O, Mauruet A, Oye I. Interaction of chiral forms of ketamine with opioid, phenyclidine and muscarinic receptors. Pharmacology and Toxicology 1995; 77: 355-359.

9. Crip T, Perroth JM, Simth DL, Stufinsky JL, Smith DJ. The local monoaminergic depending of spinal ketamine. European Journal of Pharmacology 1991; 194: 167-174.

10. Durieux ME. Inhibition by ketamine of muscarinic and acetylcholine receptor function. Anaesth and Analg 1995; 81: 57-62.
11. Brace M, Sander F, Vogel W, Hempelmann G. Blocking mechanisms of ketamine and its enantiomers in enzymetically demylinated peripheral nerve as revealed by single-channel experiments. Anaesthesiology 1997; 86: 394404.

12. Shigihara A, Suzuki M, Kumanda Y, Akama Y, Tase C, Okuaki A. Use of Ketamine combined with local anaesthetics in epidural anaesthesia. Masui 1995; 44 (4): 583 - 587.

13. Richarad W, Rosenquist, Rosenberg J. Postoperative pain guidelines. Regional anaesthesia and pain medicine 2003 ; 28 : 279 288.

14. Choe H, Choi YS, Kim YH, Ko SH, Choi HG, Han YJ, Song HS. Epidural morphine plus ketamine for upper abdominal surgery; improved analgesia from preincisional versus postincisional administration - Anaesthesia Analgesia 1997; 84 (3): 560 - 563.

15. Havdala HS, Borison RL, Diamond BI. Ketamine anaesthesia and analgesia: neurochemical differentiation. Anaesthesiology 1988; 53: S57

16. Tung AS, Yaksh TL. Analgesic effect of intrathecal ketamine in the rat. Regional Anesthesia 1981; 6: 91-94.

17. Martin D, Lodge D. Ketamine acts as a non competitive N-methyl-D-aspartate antagonist on frog intrathecal cord in Vitro. Neuropharmacology 1985; 24: 999-1003.

18. Tamamura T, Harada K, Okamura A, Kemmatsuo. Is the site of action of ketamine anaesthesia the $\mathrm{N}$-methyl-D-aspartate receptor? Anaesthesiology 1990; 72(4): 704-710.

19. Smith DS, Bouchal RL, De Sanctis CA, Monroe PJ, Amedro JB, Peroth' JM, Crisp T. Properties of the interaction between ketamine and opiate binding sites in vivo and vitro. Neuropharmacology 1987; 26:1253-1260.

20. Abram SE, Hogan QH: Neural blockade for diagnosis and prognosis: a review, Anaesthesiology 1997; 86: 2-6.

21. Naguib M, Abu-Gyamfi Y, Absood GH, Farag H, Gassy HK. Epidural ketamine for postoperative analgesia. Canadian Anaesthetists Society Journal 1986; 33:16-21. 